\title{
Meeting the Outcome-based CEAB Accreditation Criteria: Engineering Programs at UOIT
}

\author{
Hossam A. Kishawy, Tarlochan Sidhu, Remon Pop-Iliev, Marc A. Rosen, Dan Zhang, Qusay H. Mahmoud \\ Faculty of Engineering and Applied Science \\ University of Ontario Institute of Technology \\ Corresponding Author E-mail Address: hossam.kishawy@uoit.ca
}

\begin{abstract}
This paper focuses on the process of incorporating the outcome-based accreditation system based on graduate attributes and the continual improvement process into the curricula of the engineering programs at UOIT. Periodic program restructuring cycles based on a sound reporting process have been established and implemented. Thereby, systematic measurement strategies of student competencies relative to each learning outcome have been facilitated while simultaneously ensuring timely curriculum improvements.
\end{abstract}

Keywords: accreditation, graduate attributes, lifelong learning, continual improvement, feedback loop.

\section{INTRODUCTION}

A basic feature of outcome-based education (OBE) is an assessment/reporting process and a perpetual curriculum improvement cycle [1]. To ensure better learning practices and to bridge the gap between the learning experiences of engineering graduates and the evolving $21^{\text {st }}$ century job market, twelve graduate attributes have recently become an essential requirement for assessing and granting Canadian Engineering Accreditation Board (CEAB) accreditation to engineering programs in Canadian universities. In this context, since 2014, it has become mandatory to deliberately cover the twelve graduate attributes in different courses at different levels of complexity throughout the engineering curriculum, as competencies related to these graduate attributes must be ensured by the end of a program of study by each engineering graduate as the desired and required outcome. In addition, a continual improvement process must be demonstrated for engineering programs to ensure that engineering programs evolve appropriately and mitigate weaknesses.

The CEAB outcome-based method for the evaluation of engineering programs identifies 12 graduate attributes (GAs) as essential to any engineering program seeking CEAB accreditation [2]. Thus, the accreditation criteria for an engineering program require not only acceptable academic governance (program authority and responsibility) and acceptable qualitative and quantitative coverage of mathematics, natural sciences, engineering science, engineering design and complementary studies, but also the demonstration of the acquired competencies of engineering graduates as measured by a minimum number of academic units (AUs) in a broad set of graduate attributes. Fig. 1 illustrates the main pillars that must be demonstrated in any engineering accredited program.

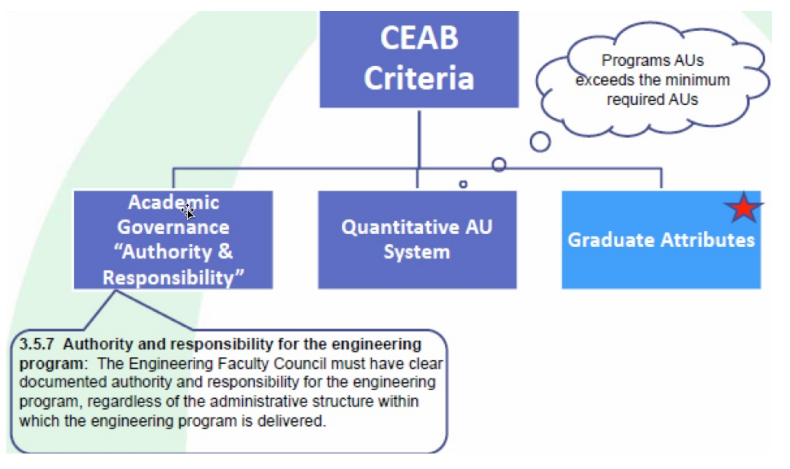

Fig. 1. Three of the main criteria for accreditation of engineering programs in Canada.

The twelve graduate attributes of the CEAB [2], which are expected to be exhibited by graduates of accredited engineering programs at the time of graduation, include:

1. A knowledge base for engineering (i.e., competence in mathematics, natural sciences, engineering fundamentals and specialized engineering knowledge appropriate to the program).

2. Problem analysis (i.e., ability to address engineering problems using appropriate knowledge and skills).

3. Investigation (i.e., ability to conduct investigations of complex problems with appropriate methods and to synthesize information).

4. Design (i.e., ability to design solutions for engineering problems and to design systems, components or processes for specified needs, with appropriate attention to health and safety, standards, economics, environmental impact, and cultural and societal considerations).

5. Use of engineering tools (i.e., ability to develop and apply engineering techniques, resources, and modern tools for engineering activities). 
6. Individual and team work (i.e., ability to work effectively as a member and leader in teams).

7. Communication skills (i.e., ability to communicate engineering concepts within the profession and with society at large).

8. Professionalism (i.e., understanding of the roles and responsibilities of the professional engineer in society).

9. Impact of engineering on society and the environment (i.e., ability to analyze and understand social and environmental aspects of engineering activities, including interactions of engineering with economic, social, health, safety, legal, and cultural aspects of society, and including sustainable design and development and environmental stewardship).

10. Ethics and equity (i.e., ability to apply professional ethics, accountability and equity).

11. Economics and project management (i.e., ability to incorporate economics and business practices in engineering practice).

12. Life-long learning (i.e., ability to identify and address one's educational needs in a changing world to maintain competence).

\section{LIFE-LONG LEARNING}

\subsection{Importance and Definition}

In the past, the now mandatory twelve graduate attributes have been usually imparted, at least implicitly, in the traditionally offered engineering programs, particularly through capstone design experiences. However, it is now expected that each of the twelve graduate attributes be explicitly identified at different levels throughout a typical four-year engineering program. This requirement, along with the need for assessing student competences for each graduate attribute that would eventually reflect into the continual improvement process for each engineering program, necessitate a comprehensive and well developed system for program self-evaluation, including a systematic approach to detailed data collection and analysis/interpretation. A capstone design course is a particularly significant example of where the majority, if not all, of the twelve graduate attributes can be demonstrated at the advanced level. However, among engineering educators, life-long learning is often considered as the graduate attribute that is most difficult to "teach," and consequently, most difficult to assess.

The importance of identifying and measuring life-long learning abilities of future engineering employees, or future members of engineering associations, has been recognized for a long number of years; hence it has become an implicit part of the routine procedures for recruiting engineers. Life-long Learning (LL), or also referred to as Continuing Professional Development (CPD), has been defined in various ways in the open literature. For the purpose of this paper, the authors adapted a hybrid definition about LL: "The process by which professionals continuously invest in the maintenance and improvement of their knowledge, skills, and competence necessary for the enhancement of the execution of professional and technical duties throughout the practitioner's working life that adds value to the resolution of clients' needs" [3,4]. Consequently, it is of no surprise that in 2008 the Canadian Engineering Accreditation Board (CEAB) published the new set of outcome-based accreditation criteria and procedures that listed LL as one of the 12 mandatory graduate attributes. This new CEAB approach to accrediting engineering programs comes into full force in the present year 2014. Similarly, the engineering educational model proposed by the $\mathrm{CDIO}^{\mathrm{TM}}$ Initiative (Conceive-Design-ImplementOperate) presented in the $\mathrm{CDIO}^{\mathrm{TM}}$ Syllabus provides a comprehensive list of engineering skills, among which for "Curiosity and Lifelong Learning [i]" CDIO ${ }^{\mathrm{TM}}$ identified the following three principal indicators: (1) the motivation for continued self-education; (2) the skills of selfeducation, and (3) one's own learning style [5]. Kirby et. al., developed a 14-item generic lifelong learning scale with reasonable reliability to measure students' disposition to engage in life-long learning. Although the research study did not involve engineering students, it can help evaluate the effectiveness of educational interventions, or allow individual students to understand their learning strengths and weaknesses [6].

\subsection{UOIT's Best Practices for $L L$}

Entertaining individually CEAB graduate attributes in isolation from the others is quite difficult because they are so often interconnected and occur simultaneously. However, it is possible to put stronger emphasis on one versus the other. Lifelong Learning is, for example, entertained in the core design engineering course MECE2310U Concurrent Engineering and Design, offered in the fall term of the second year program at the Department of Automotive, Mechanical and Manufacturing Engineering (AMME) within the Faculty of Engineering and Applied Science (FEAS) at UOIT.

It is well known that acquiring a thorough understanding of how existing bio-creatures of nature or manmade devices, processes, or systems actually function greatly facilitates the designer's cognitive process taking place when creatively solving new problems of design engineering nature. This prior knowledge enables the making of the essential connections and crucial extensions as part of the thought process of the designer or a design team. In this context, students enrolled in MECE2310U are regularly challenged with multiple questions on "how things work" type of topics during lecture contact hours, for which no answers or further explanations are provided. However, students are 
cautioned that related questions on these topics may be included in their midterm and/or final examinations. This provokes engineering curiosity at the individual's level, and motivates the students to engage in self-education to prepare the best they can by studying and doing background information research on the indicated topics, which is one form of inducing individual lifelong learning abilities. For example, one such challenging question from past exams was: "Explain how railroad vehicles with wheels fixed on the same axis can maneuver a curve on the tracks without the use of a differential. How do they run stably on both straight and curved track?" At the team level, student groups are offered several topics to choose from at the beginning of the term to conduct "case studies" and prepare a written report as well as orally present their work to the class during the term.

\section{PROGRAM STAKEHOLDERS}

A five-step action plan approach being used successfully by some of the schools across Canada and the results of the Engineering Graduate Attribute Development (EGAD) Project [7] were carefully considered. The five-step review process highlights the key elements and stages involved when undertaking a systematic comprehensive program and/or curriculum review in terms of the following five steps: 1) Program evaluation; 2) Mapping the program; 3) Identifying and collecting data on student learning; 4) Analyzing and interpreting the data; and 5) Data-informed program and/or curriculum improvement [7].

The approach taken at UOIT for conducting a systematic review of curricular structure, content, processes, and learning outcomes for its engineering programs involves all five of the steps presented above, while utilizing the $\mathrm{CEAB}$ accreditation questionnaire as a guide [8]. To facilitate the process, we grouped courses into streams and for each course stream designated a faculty member to assume the role of a Stream Leader. For UOIT's Mechanical Engineering program, for example, the defined course streams and types of designated course stream leaders are presented in Table 1. In each stream, the Stream Leader assumes responsibility to consult and to work with each course instructor in the stream and to report to the curriculum committee the appropriate graduate attributes (GAs) and the associated level at which it is covered for each course in the stream. This provide a description of the progress in terms of competence level (I: Introduced, D: Developed, A: Applied) for each attribute, while maintaining ownership of the courses with the instructors, who carry the full responsibility of delivering the courses and ensuring course outcomes are properly addressed. In order to generate a systematic process, each course instructor develops a course dossier, which includes the following main components:
Table 1. Course streams and designated stream leaders

\begin{tabular}{|l|l|l|}
\hline \multicolumn{1}{|c|}{ Course Stream } & $\begin{array}{c}\text { Faculty Member } \\
\text { Stream Leader }\end{array}$ & $\begin{array}{c}\text { UOIT } \\
\text { Home Faculty }\end{array}$ \\
\hline Math and Science & Science & Science \\
\hline Complementary studies & Social Sciences & Social Sciences \\
\hline Design Engineering & Design Chair & FEAS \\
\hline Materials \& Manufacturing & Manufacturing & FEAS \\
\hline Solid Mechanics & Solid Mechanics & FEAS \\
\hline Thermofluids & Thermofluids & FEAS \\
\hline Dynamics \& Vibrations & Dynamics & FEAS \\
\hline Robotics \& Mechatronics & Robotics & FEAS \\
\hline Electrical \& Software & Electrical & FEAS \\
\hline
\end{tabular}

1. Course-specific graduate attributes and level of coverage (I, D, A, or a combination) in the course, and their relation to the course-specific learning outcomes.

2. Relation between course outcomes and the appropriate graduate attribute indicator.

3. Definitions of performance level for each attribute/outcome (in terms of exceeds expectations, adequately meets expectations, minimally meets expectations and fails to meet expectations) and the method used to measurement the performance level (e.g., one or more questions in a final exam or assignment, laboratory report, group project).

4. Performance level grading rubric for course outcomes (i.e., course GA indicators).

5. End-of-year performance level breakdown for course outcomes (course GA indicators), and instructor comments on student performance relative to each course learning outcome recommendations regarding future changes (as part of the continual improvement process).

Once the above steps are instituted for each course and approved by the program curriculum committee, steps 1 to 4 tend to remain the same each year (except where major course changes occur). In most instances, only step 5 needs to be updated with the new student performance results each year.

\section{PROGRAM REVIEW}

In order to obtain a reliable and meaningful estimate of the actual learning levels for each program outcome, three kinds of program and/or curriculum assessment and review cycles were instituted at UOIT: formal, normal, and emergency. The details on each assessment type are depicted in the schematic presented in Fig. 2.

1. Formal three-year program curriculum review cycle (due June of the third year of the 6-year academic cycle): Formal reviews serve to evaluate the success of the implemented curricular changes within the last three years of offering the program, 
and thereby provide formative feedback to the program and the department/faculty in which it resides. That is, within the assumed maximum sixyear long accreditation cycle of a program, by default, formal program reviews of a program occur once every three years (i.e., each outcome for each course is sampled every three years).

2. Regular two-year course curriculum review cycle (due June of the second year of the 6-year academic cycle): A two-year regular course curriculum review cycle is conducted for alternative (randomly selected) streams.

3. Emergency course curriculum review cycle (due 30 days after discovery of curriculum/delivery deficiencies): This cycle is not time-prescribed, but rather is intended for "urgent" situations triggered by possible course curriculum and/or delivery problems that require immediate attention and resolution (e.g., poor teaching of a first-year course). This assessment type is necessary because, if left unresolved, such deficiencies can seriously affect program curriculum execution and thereby impede student performance in subsequent higher-level courses.

\section{CONTINUAL IMPROVEMENT PROCESS AND FEEDBACK LOOP}

A Parameter Diagram (P-Diagram) is utilized to describe the fundamental generic structure of the iterative continual program and/or curriculum improvement process and feedback loop for a program. As depicted by the schematic in Fig. 3, the generic process identifies several components and defines their assumed links and interactions. First, identified are three distinct groups of input variables that can have direct or indirect influence on the execution and performance of the Program Curriculum or Course Curriculum (i.e., the desired system), the resulting output of which is represented by a single component: the Completed CEAB Table 3.1.4 (i.e., the actual measured outcomes) in the context of the 12 CEAB graduate attributes.

The three input components of the program or course curriculum system include: Institutional Inputs (institutional academic policy-related inputs and institutional capital investment-related inputs), Noise Factors, and Updated Course Outline and Updated Course Dossier (i.e., the program or curriculum control factors and design parameters). Figure 3 provides a detailed list of the contents of each of the above input components.

\subsection{Principle of Operation}

At the time a course is offered to students, the outcomes of the course are being directly influenced by the institutional inputs, the noise factors and, most importantly, by its updated course outline and course dossier.

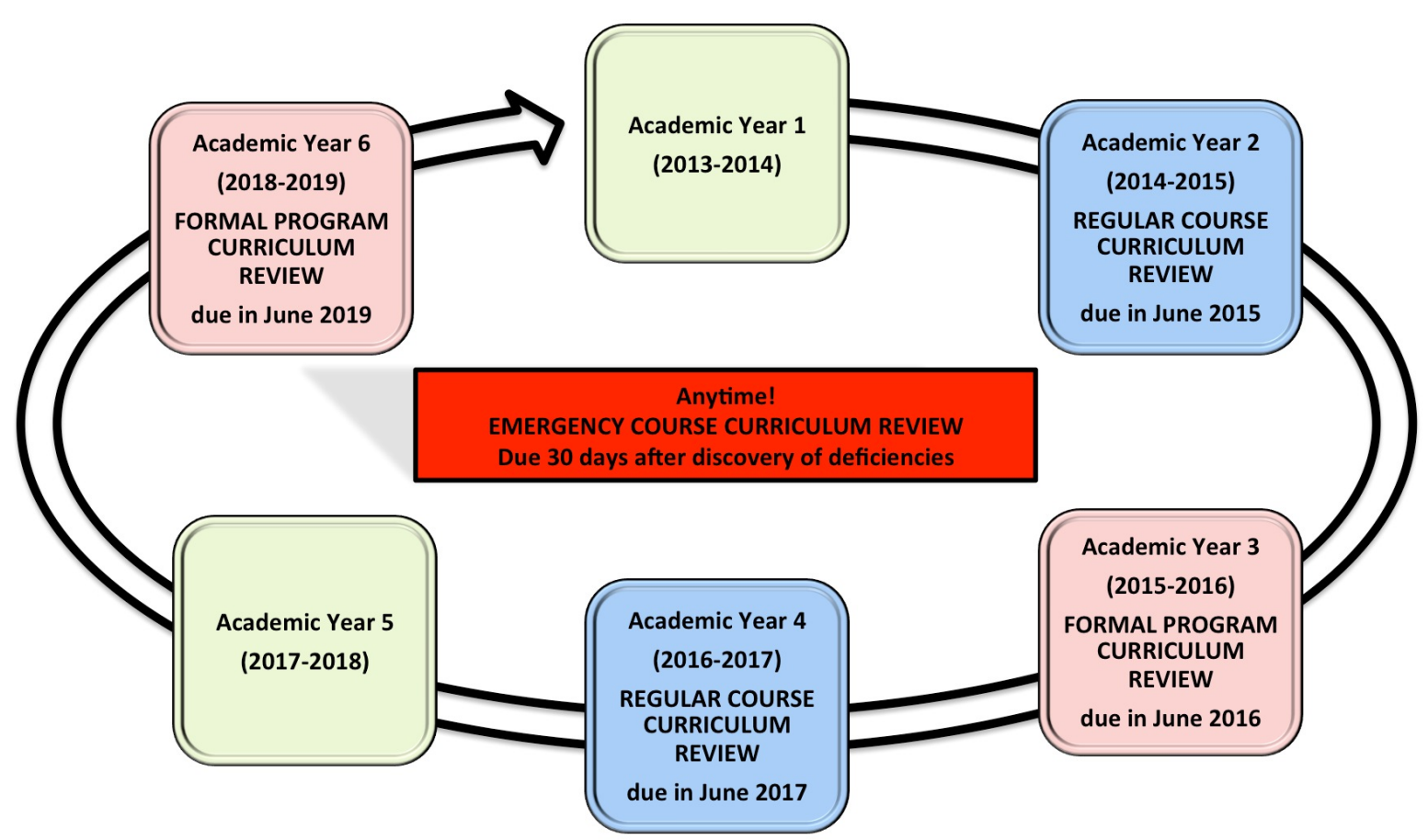

Fig. 2. Schematic of the timelines of the generic six-year regular, formal, and emergency curriculum review cycles. 
A Course Evaluation Team is created (consisting of the Stream Leader, the Course Coordinator(s) / Instructor(s), and other faculty members associated with the academic stream) for each course, with a dedicated task to compare, evaluate and assess how well the actual measured outcomes of the course, expressed through a Completed CEAB Table 3.1.4, match the desired targeted outcomes of the course expressed through Completed CEAB Tables 3.1.2 and 3.1.3 (based on the defined graduate attribute indicators belonging to the course).

If the course evaluation team finds that the results of the comparison of the assessed contents of CEAB Table 3.1.4 with the assessed contents of CEAB Table 3.1.2 reveal an $\boldsymbol{A C C E P T A B L E}$ match, no further action is needed and the course continues to be offered to the students without essential changes to the Course Outline and Course Dossier until the next evaluation period.

However, if the course evaluation team finds that the results of the comparison of the assessed contents of CEAB Table 3.1.4 with the assessed contents of CEAB Table 3.1.2 reveal a NOT ACCEPTABLE match, then the related findings are forwarded to the Program Curriculum Committee (PCC).

As a consequence, detailed remedial measures are developed and recommended by the Program Curriculum Committee in a form of a Cumulative Course Assessment and Decision Log, which is further discussed and approved by the respective academic bodies (Department Council and the Engineering Curriculum Committee), and finally forwarded for approval to the Faculty Council.

The course instructor is expected to update the course outline and course dossier and implement the changes during the next offering of the course.

\subsection{Data Collection and Analysis}

Course Evaluation Teams (CETs) conduct course assessments for each course offered in a program of study. The activities of the course evaluation team, in general, consist of monitoring the delivered instruction for agreement with planned content and course integration within the curriculum, and providing ongoing feedback for improving course content, course management, faculty teaching, and student learning experiences. Information collected should provide evidence of successes as well as suggest specific steps, resources and support needed for improvement. The plan for specific related actions includes the following nine steps:

Step 1: Relevant Stream Leader (SL) establishes a Course Evaluation Team (CET) for Course " $X$ " and informs the course's Coordinator(s)/Instructor(s) to submit the Current Course Documents Package (CCDP) for Course " $X$ " to the CET through the SL.

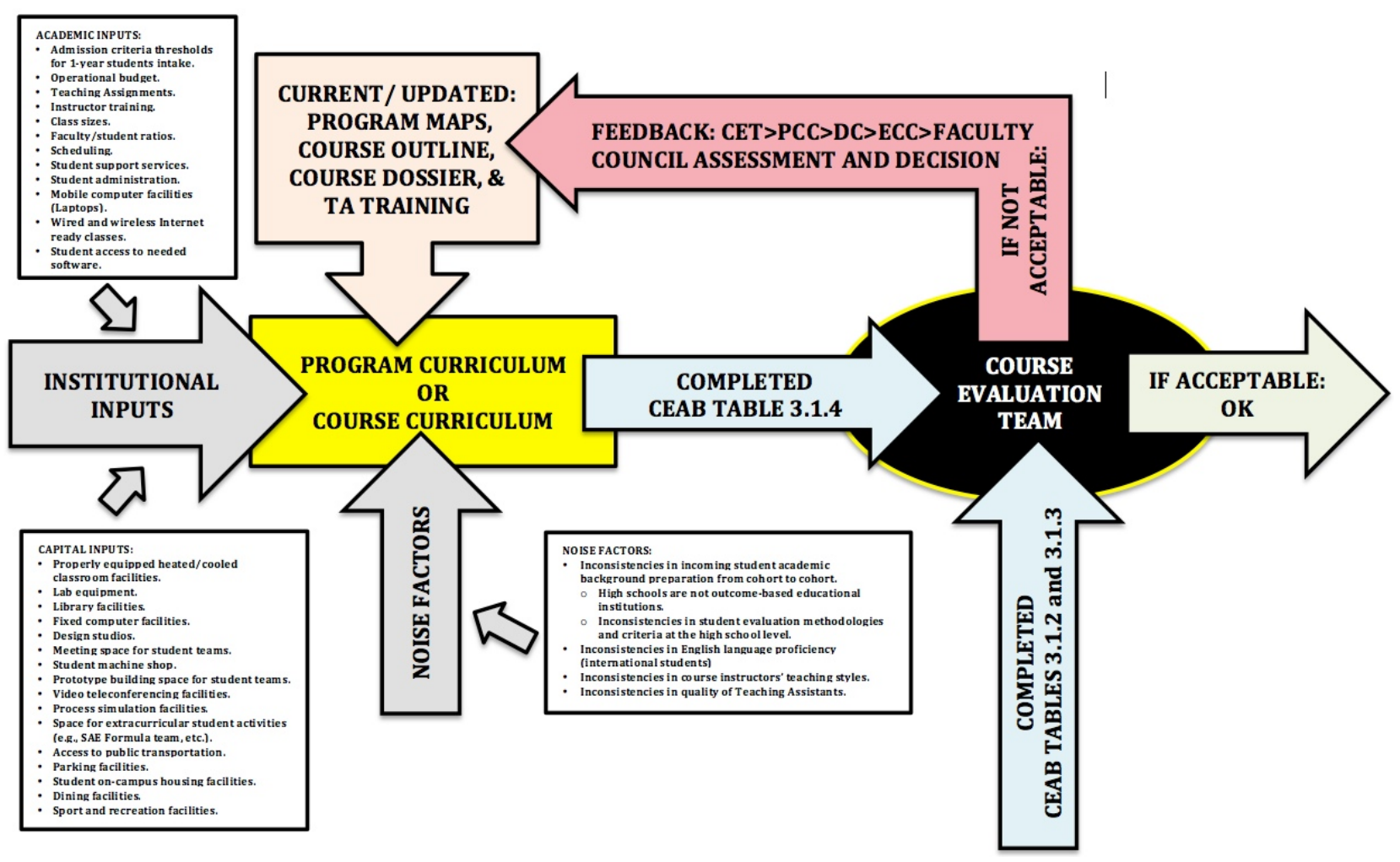

Fig. 3. Schematic of the generic continual program and/or curriculum improvement process and feedback loop. 
The CET is led by the SL in charge of the academic stream field to which the course belongs. Also, team membership includes other faculty members associated with the academic stream and the relevant course coordinator(s) / instructor(s). In principle, the organization and scope of the team activities assumes a defined leadership structure, assessment elements (performance indicators, program and/or curriculum map, and assessment schedule), assessment design (assessed courses and assessment methods), assessment data and results, and preparing proposals for future program improvements.

Step 2: Coordinator(s)/Instructor(s) of Course " $X$ " submit the Current Course Documents Package (CCDP) for that course to the Course Evaluation Team (CET) for Course " $X$."

The Course Documents Package submitted as part of this step includes:

- The current Course Outline prepared by the course coordinator/instructor.

- The Current Course Dossier (i.e., Completed CEAB Tables 3.1.2 and 3.1.3) prepared by the course coordinator/instructor).

- Current Course Coordinator/Instructor SelfAssessment report (Completed CEAB Table 3.1.4) prepared by the course coordinator/instructor.

- Current official Student Course Evaluations.

Step 3: Course Evaluation Team for Course " $X$ " meets, considers and analyses the Current Course Documents Package (CCDP) submitted by the Course Coordinator(s)/Instructor(s) and generates a Course Assessment Report (CAR) for Course " $X$ " that is submitted to the relevant Program Curriculum Committee (PCC) for review and approval.

The course evaluation teams are, in principle, charged with the following activities:

- Collect, inspect, scan and file data each term (enter inspection results in a Data Collection Log; place scanned data online).

- For each course outcome, extract relevant data from files, following the Program Outcome Assessment Schedule.

- Process data to estimate actual learning level for each course outcome.

- Identify the areas needing improvement and suggest appropriate changes.

- Improvements should be achieved in course policy standardization, course integration within the curriculum, faculty teaching behaviors, and student experiences.

- For each course outcome/graduate attribute, if the desired learning level is not achieved (e.g., lack of opportunities for student self-assessment and selfregulated learning have resulted in only $42 \%$ of students reaching threshold levels in Lifelong Learning).

- Analyze the explanation offered about the findings per course and per graduate attribute (provided by course instructors each time the course is offered).

- Generate speculations about possible interrelationships with other courses (e.g., prerequisites or co-requisites).

- Identify the probable causes and reasons for the findings and decide on a course of action (define the remedial measures).

The Course Evaluation Team is in charge of generating and agreeing on the Course Assessment Report (CAR), which is then submitted to the Program Curriculum Committee for review and approval.

Step 4: Program Curriculum Committee (PCC) Course Assessment Report (CAR) Review and Approval.

Once the Program Curriculum Committee (PCC) receives and considers the Course Assessment Report (CAR) generated by the Course Evaluation Team (CET), the PCC converts its related and detailed decisions into a Modified Course Assessment Report (MCAR), which is then submitted to the Department Council (DC) for review and approval.

Step 5: Department Council (DC) Modified Course Assessment Report Approval.

The Department Council (DC) may approve or reject the Modified Course Assessment Report (MCAR). If the MCAR is approved, it is then submitted to the Engineering Curriculum Committee (ECC) for review and approval.

Step 6: Engineering Curriculum Committee (ECC) Modified Course Assessment Report (MCAR) Review and Approval.

Once the Engineering Curriculum Committee (ECC) receives and considers the Modified Course Assessment Report (MCAR) generated by the Program Curriculum Committee (PCC) and approved by the Department Council (DC), the ECC converts its related and detailed decisions into a Final Course Assessment Report (FCAR), which is then submitted to the Faculty Council (FC) for review and approval.

Step 7: Faculty Council (FC) Final Course Assessment Report (FCAR) Approval.

The Faculty Council (FC) may approve or reject the Final Course Assessment Report (FCAR). If the FCAR is approved, the FC formally charges the Course " $\mathrm{X}$ " Coordinator/ Instructor (CC/I) on behalf of the Dean to update the Current Course " $\mathrm{X}$ " Outline and Dossier according to the approved FCAR and to continue offering course "X" according to the updated documents. 
Step 8: Stream Leader (SL) creates a Cumulative Course Assessment Report File (CCARF) for Course " $X$."

The Stream Leader (SL) adds the latest approved Final Course Assessment Report (FCAR) to the Cumulative Course Assessment Report File (CCARF), archives the CCARF in both electronic and hard copy format and formally provides a copy of the latest FCAR to the Dean for purpose of relevant faculty performance evaluation.

Step 9: Course Coordinator/Instructor (CC/I) for Course " $X$ " updates the Current Course Documents Package (CCDP) for Course " $X$."

The Coordinator/Instructor updates the current course outline for Course " $\mathrm{X}$ " and the Current Course " $\mathrm{X}$ " Dossier (i.e., Completed CEAB Tables 3.1.2 and 3.1.3) according to the approved FCAR. Also, the Coordinator/Instructor implements all the required and recommended changes during the next offering of the Course "X". Finally, the Coordinator/Instructor collects, summarizes and analyses all outcome-based assessment data of the newly offered course related to the $12 \mathrm{CEAB}$ Graduate Attributes and creates a new Current CEAB Table 3.1.4 to be used for the next review cycle. That may be a Formal 3-year Program Review, or a Regular 2-year Course Review, or an Emergency Course Review, as appropriate.

\section{CONCLUSIONS}

The recent experience at UOIT in demonstrating the competencies required for accreditation for engineering programs is considered. The process of incorporating the graduate attributes and the continual improvement process into the curricula of engineering programs at UOIT is presented, with the objective of describing one approach and seeking feedback and suggestions on possible enhancements. In particular, the process used to develop a systematic approach for measuring performance relative to graduate attributes and learning outcomes and the results of its application to the continual improvement cycle of UOIT's engineering programs is demonstrated.

\section{References}

[1] Tucker, B. 2004. Literature Review: Outcomes-focused Education in Universities. Learning Support Network, Curtin University of Technology. Retrieved October 19, 2004 http://sn.curtin.edu.au/outcomes/docs/LitReview.pdf.

[2] Engineers Canada, "Accreditation Criteria and Procedures Report 2013 (Accreditation Visit Cycle 2014 - 2015),” CEAB.

[3] Graham Guest, (2006), "Lifelong learning for engineers: a global perspective," European Journal of Engineering Education, Vol. 31, No. 3, pp. 273-281.
[4] Rolf Johan Lenschow, (1998), "From Teaching to Learning: A Paradigm Shift in Engineering Education and Lifelong Learning," European Journal of Engineering Education, Vol. 23, No. 2, pp. 155-161.

[5] Edward F. Crawley, Johan Malmqvist, William A. Lucas, and Doris R. Brodeur, (2011), "The CDIO Syllabus v2.0 An Updated Statement of Goals for Engineering Education," in Proceedings of the 7th International CDIO Conference, Technical University of Denmark, Copenhagen, June $20-23,2011$.

[6] John R. Kirby, Christopher Knapper, Patrick Lamon, and William J. Egnatoff, (2010), "Development of a scale to measure lifelong learning", International Journal of Lifelong Education, Volume 29, Issue 3, pp. 291-302.

[7] EGAD Project, http://egad.engineering.queensu.ca

[8] Engineers Canada, "Complete questionnaire 2012 (Accreditation Visit Cycle 2013 - 2014),” CEAB. 